\title{
Experience-Dependent versus Experience-Independent Postembryonic Development of Distinct Groups of Zebrafish Olfactory Glomeruli
}

\author{
Oliver R. Braubach, ${ }^{1,2,3}$ Nobuhiko Miyasaka, ${ }^{4}$ Tetsuya Koide, ${ }^{4}$ Yoshihiro Yoshihara, ${ }^{4}$ Roger P. Croll,,${ }^{1,2}$ and Alan Fine ${ }^{1,2}$ \\ ${ }^{1}$ Department of Physiology and Biophysics and ${ }^{2}$ eeuroscience Institute, Dalhousie University, Halifax, Nova Scotia B3H 4H7, Canada, ${ }^{3}$ WCI Center for \\ Functional Connectomics, Korea Institute of Science and Technology, Seoul 136-791, Korea, and ${ }^{4}$ Laboratory for Neurobiology of Synapse, RIKEN Brain \\ Science Institute, Saitama 351-0198, Japan
}

\begin{abstract}
Olfactory glomeruli are innervated with great precision by the axons of different olfactory sensory neuron types and act as functional units in odor information processing. Approximately 140 glomeruli are present in each olfactory bulb of adult zebrafish; these units consist of either highly stereotypic large glomeruli or smaller anatomically indistinguishable glomeruli. In the present study, we investigated developmental differences among these types of glomeruli. We observed that 10 large and individually identifiable glomeruli already developed before hatching, at $72 \mathrm{~h}$ after fertilization, in configurations that resembled their mature organization. However, the cross-sectional area of these glomeruli increased throughout larval development, and they eventually comprised the largest units in postlarval olfactory bulbs. In contrast, small and anatomically indistinguishable glomeruli formed only after hatching, apparently by segregating from five larger precursors that were identifiable during embryonic development. The differentiation of these small glomeruli proceeded with conspicuous variation in number and arrangement, both among larvae and between olfactory bulbs of the same individuals. To determine factors that might contribute to this variability, we investigated the effects of olfactory enrichment on the development of amino acid-responsive lateral glomeruli, which include both large and small units. Larvae reared in an amino acidenriched environment had normal large lateral glomeruli, but the small lateral glomeruli were more numerous and displayed reduced cross-sectional areas compared with glomeruli in control animals. Our results suggest that large and small glomeruli mature via distinct developmental processes that may be differentially influenced by sensory experience.
\end{abstract}

\section{Introduction}

In vertebrates, odors are transduced by large arrays of different olfactory sensory neuron (OSN) types widely distributed across the sensory epithelia (Ressler et al., 1993; Vassar et al., 1993). OSN afferent axons become highly organized when they enter the brain, and all axons originating from a single OSN type (i.e., expressing a par-

Received Nov. 4, 2012; revised Feb. 6, 2013; accepted March 3, 2013.

Author contributions: 0.R.B., N.M., R.P.C., and A.F. designed research; 0.R.B. performed research; N.M., T.K., and Y.Y. contributed unpublished reagents/analytic tools; O.R.B., R.P.C., and A.F. analyzed data; 0.R.B., N.M., T.K., Y.Y., R.P.C., and A.F. wrote the paper.

This work was supported by Natural Sciences and Engineering Research Council of Canada Discovery Grant RGPIN170421 to A.F. and Grant 38863 to R.P.C., Canadian Institutes of Health Research Operating Grant MOP49489 to A.F., Ministry of Education, Culture, Sports, Science and Technology of Japan KAKENHI Grant 23115723 to Y.Y., and Human Frontier Science Program Research Grant RGP0015/2010 to Y.Y. O.R.B. was supported by the Nova Scotia Health Research Foundation predoctoral fellowship MED-SRA-2006-5242, World Class Institute/National Research Foundation of Korea Grant KRF: WCI 2009-003, and National Institutes of Health Grant DC005259-39. The SV2 antibody was obtained from the Developmental Studies Hybridoma Bank developed under the auspices of the NICHD and maintained by the University of lowa Biology Department. We thank Dr. Koichi Kawakami for kindly providing SAGFF27A;UAS:GFP zebrafish. We thank Drs. Thomas Finger, Frank Smith, and Richard Brown and members of the R.P.C., A.F., and Y.Y. laboratories for their assistance with experiments and criticisms of earlier versions of this manuscript; and Dr. Lawrence B. Cohen for permitting 0.R.B. to continue work on this manuscript while at the Korea Institute of Science and Technology and Yale University.

The authors declare no competing financial interests.

Correspondence should be addressed to either Dr. Roger P. Croll or Dr. Alan Fine, Department of Physiology \& Biophysics, Dalhousie University, Halifax, Nova Scotia B3H 4H7, Canada. E-mail: roger.croll@dal.ca or a.fine@dal.ca. DOI:10.1523/JNEUROSCI.5185-12.2013

Copyright $\odot 2013$ the authors $\quad 0270-6474 / 13 / 336905-12 \$ 15.00 / 0$ ticular olfactory receptor) converge onto specific glomeruli in the olfactory bulbs (OBs). Certain glomeruli in mammals (Schaefer et al., 2001; Oliva et al., 2008) and lower vertebrates (Baier and Korsching, 1994) have consistent locations and are accessible for repeated study (e.g., Potter et al., 2001). However, because of the sheer number of glomeruli typically present in vertebrate olfactory systems, there is little known about glomerular distributions throughout the life cycle of single species (but see Gaudin and Gascuel, 2005), and even less about the developmental mechanisms that form and maintain vertebrate glomerular maps. Here, we address these issues in zebrafish, a useful model for understanding the ontogeny and functional organization of vertebrate olfactory systems.

The development of the zebrafish olfactory system begins $\sim 22$ $\mathrm{h}$ post-fertilization (hpf) when transient pioneer neurons in the olfactory placodes extend fibrous processes to the developing forebrain (Hansen and Zeiske, 1993; Whitlock and Westerfield, 1998). Ingrowing OSN axons follow these processes and, beginning at $\sim 48 \mathrm{hpf}$, contact postsynaptic targets to form rudimentary glomeruli (Whitlock and Westerfield, 1998; Miyasaka et al., 2007). Most glomeruli appear to differentiate during larval development (Li et al., 2005), and their numbers increase more than 10-fold between prehatching embryos (Dynes and Ngai, 1998) and adults (Braubach et al., 2012). The olfactory system of adult zebrafish contains $\sim 140$ glomeruli, arranged in distinct groups that are innervated by specific OSN classes (Braubach et al., 
2012). Lateral glomeruli, for example, are innervated mostly by microvillous OSNs (Sato et al., 2005) responsive to amino acids (Friedrich and Korsching, 1997, 1998; Koide et al., 2009). In contrast, glomeruli in the medial $\mathrm{OB}$ are innervated preferentially by ciliated OSNs (Sato et al., 2005) responsive to bile acids (Friedrich and Korsching, 1998). Zebrafish glomeruli can be further discriminated based on anatomical criteria (Braubach et al., 2012). For example, 25 glomeruli are relatively large and present in essentially the same arrangement in every animal. Some of these glomeruli are selectively labeled with markers for certain G-protein subunits $\left(\mathrm{G}_{\text {olf }}\right.$ or $\left.\mathrm{G}_{\alpha \mathrm{o}}\right)$ or calciumbinding proteins (calretinin or S100). The remaining glomeruli ( $85 \%$ of total population) are comparatively small and arranged in inconsistent manners. Most of these glomeruli are innervated by OSNs that are doublelabeled with markers for $\mathrm{G}_{\text {olf }}$ and calretinin.

Here, we provide a detailed description of glomerular development and patterning during the first 6 weeks of development, beginning just before hatching. Furthermore, we examine the role of experience in shaping the development of different types of glomeruli. We report that large, individually identifiable glomeruli differentiate early and consistently, retaining nearly identical numbers and distributions afterward. In contrast, small anatomically indistinguishable glomeruli develop after hatching, with conspicuous variations between animals in a manner that may be influenced by sensory input.

\section{Materials and Methods}

Morphological analysis: animals and tissue processing. Adult zebrafish ( $\mathrm{AB}$ strain, University of Oregon) were maintained according to standard guidelines (Nüsslein-Volhard and Dahm, 2002). Embryos, obtained by breeding adult fish during the first hour of the light period, were kept in tubes with mesh bottoms (depth, 8 $\mathrm{cm}$; height, $7 \mathrm{~cm}$ ) in a flow-through nursery unit at $28.5^{\circ} \mathrm{C}$. The nursery unit was supplied with a continuous drip of fresh municipal water filtered through a series of sand and charcoal filters. Starting at $5 \mathrm{~d}$ postfertilization (dpf), larvae were fed crushed flake food (Omega Sea) and live Artemia nauplii (Salt Creek). At $7 \mathrm{dpf}$, larvae were transferred to 1.5 $\mathrm{L}$ rearing tanks (Aquatic Habitats) connected to the same water source described above. Excrement and uneaten food were regularly removed. The developmental stage of embryos ( $\leq 72 \mathrm{hpf}$ ) was determined with reference to standard guidelines (Kimmel et al., 1995) (Table 1), whereas that of hatched larvae was determined by their body length (Parichy et al., 2009) (Table 1). The numbers and ages of animals used to produce data are listed throughout the Results. All experiments were conducted on animals that had not reached sexual maturity; and because of a lack of definitive sexing methods for larval zebrafish, we used male and female specimens indiscriminately. All experiments were conducted with reference to the Guide for Use of Laboratory Animals established by the Canadian Council for Animal Care.
Table 1. Experimental animals

\begin{tabular}{lcccc}
\hline & & & \multicolumn{2}{c}{ Olfactory bulbs $(\mu \mathrm{m})$} \\
\cline { 4 - 5 } Stage & Age & Length $(\mathrm{mm})$ & Anterior-posterior & Medial-lateral \\
\hline 72 hpf embryo & $72 \mathrm{hpf}$ & 3.5 & $75 \pm 5^{a}$ & $65 \pm 5$ \\
Early larva & $\geq 4 \mathrm{dpf}$ & 4.3 & $75 \pm 10$ & $65 \pm 5$ \\
Mid larva & $\geq 21 \mathrm{dpf}$ & 5.0 & $125 \pm 25$ & $80 \pm 10$ \\
Juvenile & $\geq 35 \mathrm{dpf}$ & 10.0 & $175 \pm 25$ & $170 \pm 10$ \\
\hline
\end{tabular}

${ }^{a}$ Embryonic OBs were measured ventral-dorsal.
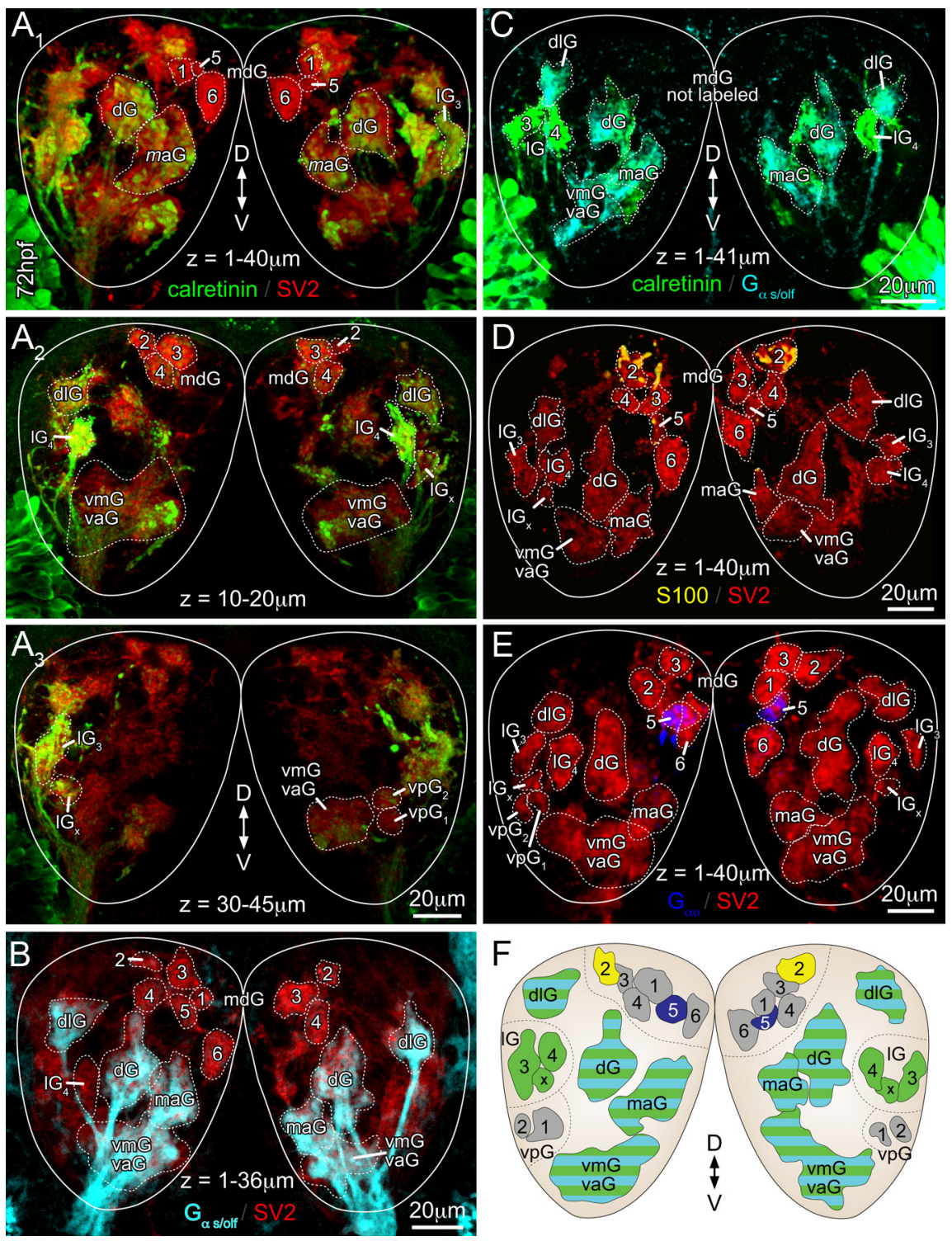

Figure 1. Frontal views of $\mathrm{OBs}$ from five $72 \mathrm{hpf}$ embryos, as seen through the skull. Glomeruli labeled selectively with anticalretinin ( $\left(\boldsymbol{A} 1-\boldsymbol{A}\right.$ 3, substacks of optical sections from same specimen), anti- $\mathrm{G}_{\alpha s / \text { off }}(\boldsymbol{B})$, anti-S100 $(\boldsymbol{D})$, and anti- $\mathrm{G}_{\alpha 0}(\boldsymbol{E})$ antibodies. Four large and irregularly shaped regions ( $\mathrm{dG}, \mathrm{dIG}, \mathrm{maG}$, and vmG/vaG) were always labeled by anti-calretinin and anti- $\mathrm{G}_{\alpha s / \text { olf }}$ antibodies $(\boldsymbol{C}, \boldsymbol{F})$. $\boldsymbol{A} 1-\boldsymbol{A} \mathbf{3}, \boldsymbol{C}, \mathrm{I}$ labeled only with the anti-calretinin antibody. The $\mathrm{mdG}_{2}$ and $\mathrm{mdG}_{5}$ were selectively immunoreactive (IR) to anti-S100 (D) and anti- $G_{\alpha 0}(\boldsymbol{E})$, respectively, and displayed inconsistent staining with the anti-calretinin antibody (compare $\boldsymbol{A 1 - C}$. The remaining $\mathrm{mdG}$ were labeled only with general structural markers, such as anti-SV2. $\boldsymbol{F}$, The schematic summarizes the distributions of glomeruli at $72 \mathrm{hpf}$. The scale bar in $\mathbf{A} \mathbf{3}$ also applies to $\mathbf{A 1}, \boldsymbol{A} \mathbf{2}$.

Embryonic and larval zebrafish were killed by immersion in ice-cold water $\left(<4^{\circ} \mathrm{C}\right)$ for $\sim 1 \mathrm{~min}$ (Macdonald, 1999). Whole embryos and heads of larvae were then fixed by immersion in fresh $2 \%$ PFA (Electron Microscopy Sciences) in PBS (100 mM $\mathrm{Na}_{2} \mathrm{HPO}_{4}, 140 \mathrm{~mm} \mathrm{NaCl}$, pH 7.4) for $6 \mathrm{~h}$ at room temperature or overnight at $4^{\circ} \mathrm{C}$. Brains were then dissected 
Table 2. Antibodies, their sources, and concentrations used

\begin{tabular}{|c|c|c|}
\hline Antibody & Immunogen/host & Source \\
\hline \multicolumn{3}{|l|}{ General labels (1:100 in PBS-T) } \\
\hline Anti-KLH (1:100 dilution) & $\mathrm{KLH} / \mathrm{rabbit}$ & Sigma (H0892) \\
\hline Anti-SV2 (1:100 dilution) & Diplobatis ommata synaptic vesicles/mouse & Developmental Studies Hybridoma Bank \\
\hline \multicolumn{3}{|c|}{ OSN-type specific labels (1:50 -1:200 in PBS-T) } \\
\hline Anti- $G_{\alpha s / \text { olf }}(1: 50$ dilution $)$ & Rat c-terminus (amino acids 377-394): rabbit & Santa Cruz Biotechnology (sc-383) \\
\hline Anti-G ${ }_{\alpha 0}(1: 50$ dilution) & Rat divergent domain (amino acids 105-124): rabbit & Santa Cruz Biotechnology (sc-387) \\
\hline Anti-calretinin (1:200 dilution) & Recombinant human calretinin/mouse and rabbit & Swant $6 \mathrm{~B} 3$ and $7699 / 3 \mathrm{H}$ \\
\hline Anti-S100 (1:100 dilution) & Purified cow S100 protein: rabbit & Dako Denmark (Z 0311) \\
\hline
\end{tabular}
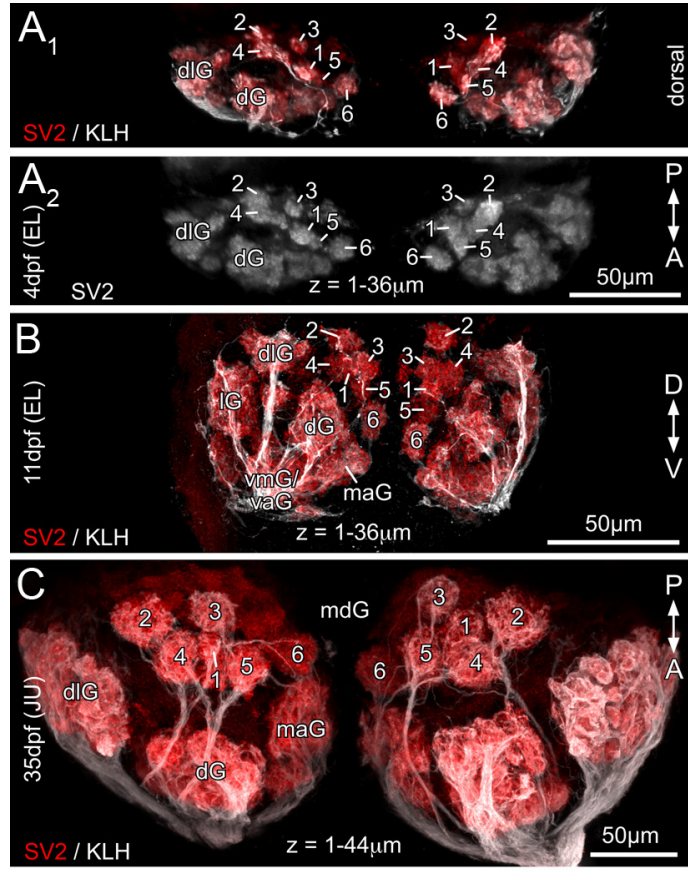

$\mathrm{D}$
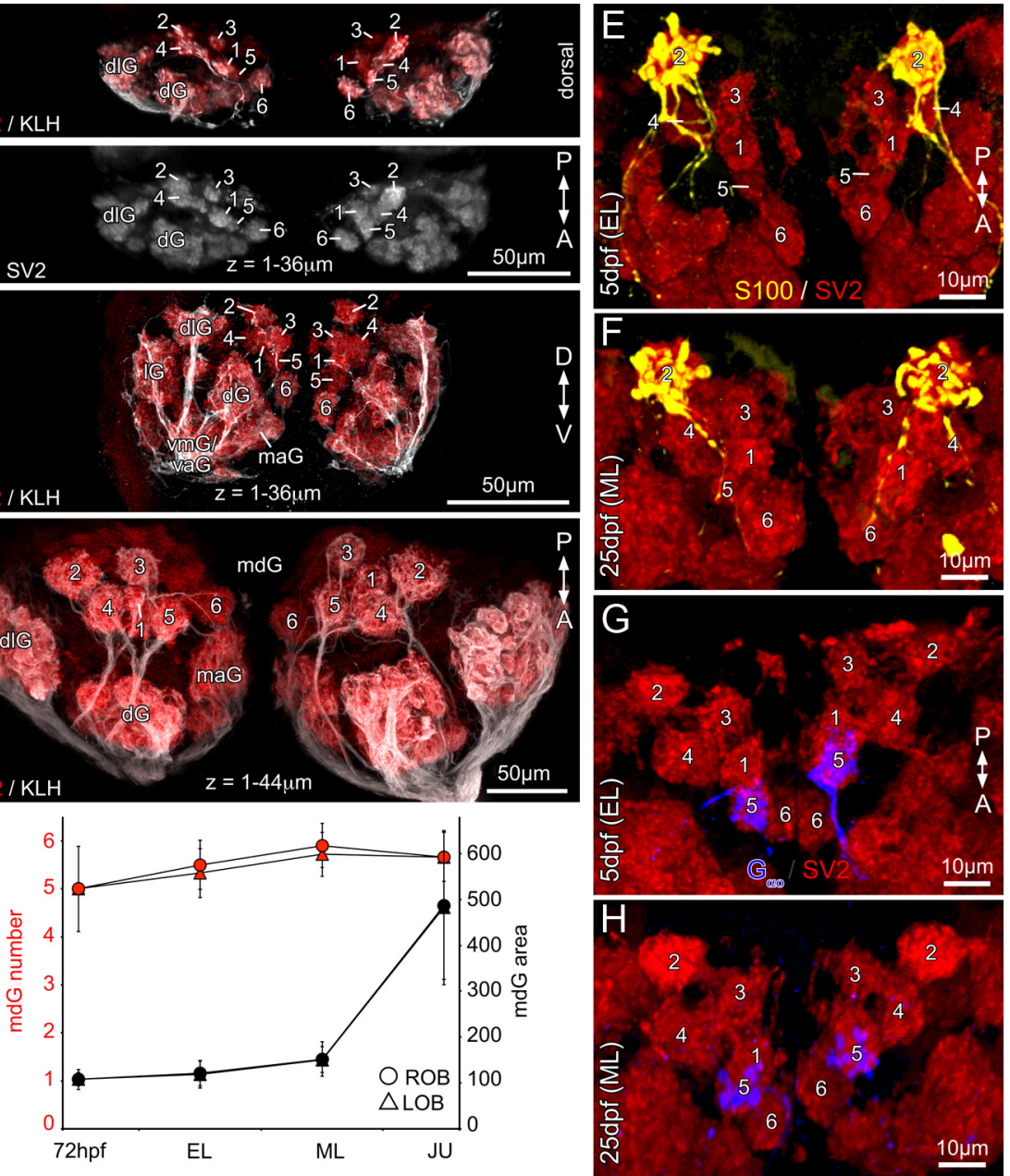

Figure 2. Maximum intensity confocal projections of dorsal OBs during larval development. $\boldsymbol{A}-\boldsymbol{C}$, The mdG were arranged in approximately triangular clusters and were individually identifiable (as numbered) throughout larval development. All mdG labeled with anti-KLH and anti-SV2 antibodies. The identification of individual mdG was aided by use/comparison of multiple anatomical labels (compare $\boldsymbol{A} \mathbf{1}$ with $\boldsymbol{A} \mathbf{2}$ : same specimen). D, Summary plot showing the numbers (red) and sizes (black) of mdG per $O B$ throughout embryonic and larval development. Data are mean \pm SD; numbers from 5 animals per developmental stage. The S100-IR mdG $\left(\boldsymbol{E}, \boldsymbol{F}\right.$, yellow) and the $G_{\alpha 0}-I_{R d G}(\boldsymbol{G}, \boldsymbol{H}$, blue $)$ retained the same positions throughout larval development. Scale bar in $\mathbf{A 2}$ also applies to $\mathbf{A 1}$. EL, Early larva; ML, mid-larva; JU, juvenile; $L O B$ and ROB, left and right $O B$.

and washed four times in PBS over $2 \mathrm{~h}$ and immersed in a PBS-based blocking solution containing $0.25 \% \mathrm{v} / \mathrm{v}$ Triton X-100, $2 \% \mathrm{v} / \mathrm{v}$ dimethylsulfoxide, $1 \% \mathrm{v} / \mathrm{v}$ normal goat serum and $1 \% \mathrm{w} / \mathrm{v}$ bovine serum albumin (PBS-T; all from Sigma) for $\geq 12 \mathrm{~h}$ at $4^{\circ} \mathrm{C}$. Unless noted otherwise, PBS-T was used for all subsequent washing steps (e.g., after primary and secondary antibody incubation), and each washing step consisted of five rinses with PBS-T over a period of $\sim 4 \mathrm{~h}$.

Antibody characterization. All antibodies used in this study were characterized previously in the zebrafish olfactory system (Table 2) (see also Braubach et al., 2012). Briefly, we used a combination of anti-keyhole limpet hemocyanin (KLH) and anti-synaptic vesicle protein 2 (SV2) to label the presynaptic compartments of glomeruli. To study the neurochemistry of certain glomeruli, we stained OBs with antibodies against the G-protein $\alpha$ subunits $G_{\alpha s / o l f}$ and $G_{\alpha o}$ and the calciumbinding proteins calretinin and S100.

Immunocytochemistry. Mixtures of two primary antibodies were diluted in PBS-T, and tissue was incubated in these solutions for $5-7$ $\mathrm{d}$ at $4^{\circ} \mathrm{C}$ with gentle agitation. The tissue was then washed and incubated in a mixture of appropriate goat anti-rabbit IgG antibodies and goat anti-mouse $\operatorname{IgG}$ antibodies conjugated to either AlexaFluor-488 or AlexaFluor-555 (both from Invitrogen; diluted 1:50 to 1:100 in PBS-T) or CY5 (Jackson ImmunoReseach Laboratories) for $4-5 \mathrm{~d}$ at $4^{\circ} \mathrm{C}$.

Before mounting, brains were washed and immersed for $24 \mathrm{~h}$ in a 3:1 solution of glycerol and $0.1 \mathrm{~m}$ Tris buffer, $\mathrm{pH} 8.0$, containing $2 \%$ $(\mathrm{w} / \mathrm{v}) n$-propyl gallate (all from Sigma). Brains were then mounted in fresh glycerol solution between two coverslips (separated with stacks of coverslip fragments to minimize compression) and sealed with nail polish.

Microscopy, image analysis, and processing. Specimens were viewed with an LSM 510 or LSM 510 META laser scanning confocal microscope (Carl Zeiss). Optical sections were viewed and processed with ImageJ software (http://rsb.info.nih.gov/ij), and glomeruli were identified and mapped based on previously established criteria (Braubach et al., 2012). Briefly, glomeruli were counted and measured by stepping through optical sections and identifying OSN axons that enveloped spheroidal structures tentatively identified as glomeruli. Average counts and sizes of glomeruli were based on observations from at least five fish at each developmental stage. Glomeruli that were identified in four or more of these specimens were assigned specific names (e.g., lateral glomerulus $1 G_{3}$ ), whereas the remaining units were only assigned to appropriate regions (e.g., lateral glomerulus $\mathrm{lG}_{\mathrm{x}}$ ). Glomerular maps therefore depict the characteristic arrangement of all repeatedly identifiable glomeruli plus the approximate distributions of glomeruli that were not unambiguously identifiable.

Glomerular nomenclature was used as established previously (Braubach et al., 2012) but was modified to accommodate developmental changes among certain glomeruli. Specifically, most glomeruli that were identified during embryonic development reorganized after hatching, thus preventing their unambiguous identification in successive developmental stages. These glomeruli are initially referred to via their association with a certain $\mathrm{OB}$ region. 

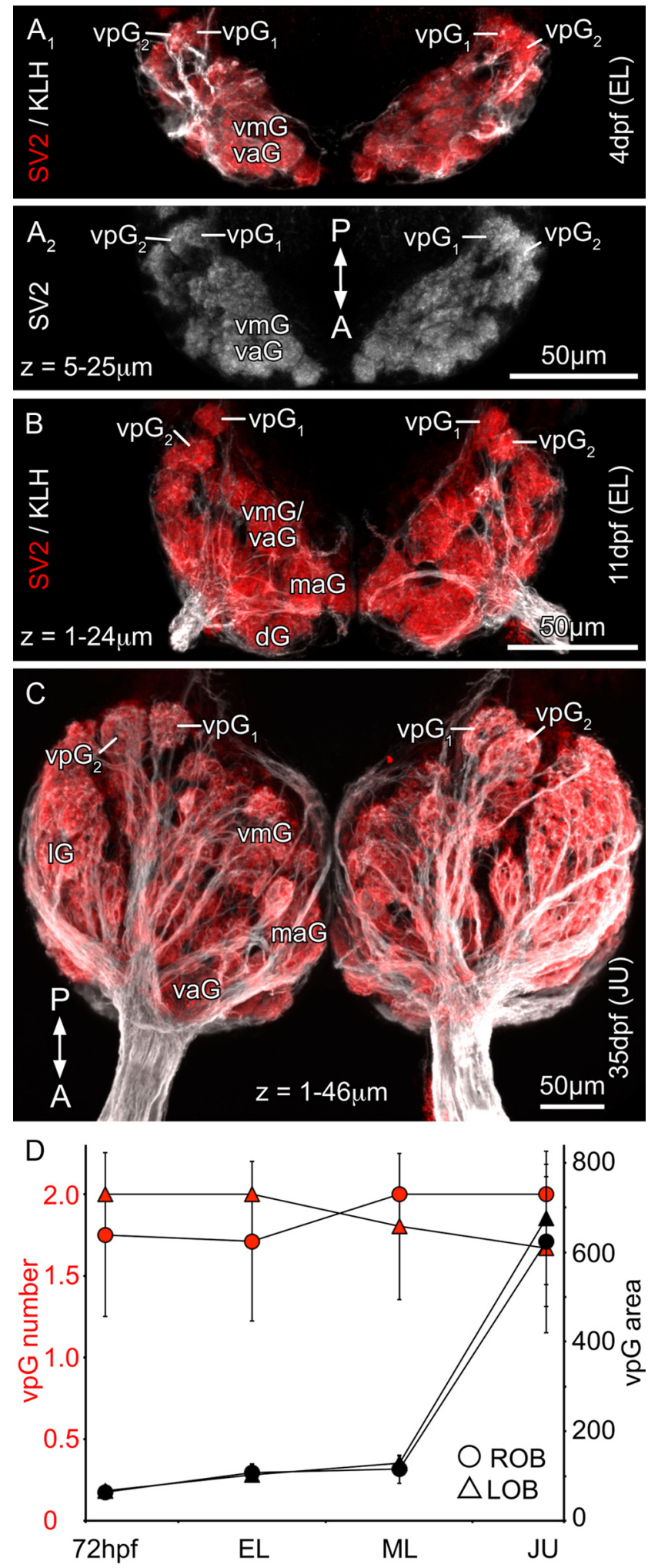

Figure 3. Maximum intensity confocal projections of ventral OBs at different developmental stages stained with anti-KLH and anti-SV2 antibodies (as indicated); the vpG were unambiguously identifiable in the ventroposterior $0 B s(\boldsymbol{A}-\boldsymbol{C}, \mathrm{vpG}) . \boldsymbol{D}$, The plot shows the numbers (red) and sizes (black) of vpG per $0 B$ throughout embryonic and larval development. Data are mean \pm SD; numbers from 5 animals per developmental stage. The scale bar in $\mathbf{A} \mathbf{2}$ also applies to $\mathbf{A 1}$. EL, Early larvae; ML, mid-larva; JU, juvenile; $L O B$ and $R O B$, left and right $O B$.
Confocal images shown here are maximum intensity projections of serial optical sections obtained at $1 \mu \mathrm{m}$ intervals to a maximum depth of 60-80 $\mu \mathrm{m}$ (as indicated in each figure). Three-dimensional reconstructions were created with the ImageJ 3D viewer (Schmid et al., 2010); resulting images were adjusted for brightness and contrast in Photoshop, and figure plates and drawings were created with InDesign and Illustrator (all from Adobe Systems).

Olfactory enrichment experiments. To study the modification of glomerular development by experience, we used a transgenic zebrafish line expressing GFP restricted to amino acid-responsive OSNs innervating lateral glomeruli, as described previously by Koide et al. (2009). Briefly, SAGFF27A transgenic adult zebrafish expressing a transcription activator GAL4FF, as well as UAS:GFP reporter fish (Asakawa et al., 2008), were maintained according to standard guidelines at the RIKEN Brain Science Institute. SAGFF27A;UAS:GFP double-transgenic embryos were obtained by crossing adult fish and screening for fluorescence in lateral glomeruli. Positive embryos were maintained at $28.5^{\circ} \mathrm{C}$ in zebrafish Ringer solution (39.0 mM NaCl, $1.0 \mathrm{~mm} \mathrm{KCl,} 1.8 \mathrm{~mm} \mathrm{CaCl}_{2}$, and $1.7 \mathrm{~mm}$ HEPES, pH 7.2) supplemented with $100 \mathrm{U} / \mathrm{ml}$ penicillin and $100 \mu \mathrm{g} / \mathrm{ml}$ streptomycin. Pigmentation was suppressed by adding $0.002 \%$ phenylthiourea (Nacalai Tesque) to the rearing medium from $12 \mathrm{hpf}$ to a maximum of $36 \mathrm{hpf}$.

Immediately after hatching ( $\sim 72 \mathrm{hpf})$, larvae were imaged with a confocal microscope (see below) and then transferred individually or in pairs to small rectangular mesh chambers (length $=4.0 \mathrm{~cm}$, width $=1.2 \mathrm{~cm}$, height $=2.0 \mathrm{~cm}$ ) inside a custom-built nursery unit, consisting of an acrylic tank (length $=18 \mathrm{~cm}$, width $=12 \mathrm{~cm}$, height $=1.5 \mathrm{~cm}$ ) through which a constant flow $(60 \mathrm{ml} / \mathrm{min})$ of fresh dechlorinated water $\left(28.5^{\circ} \mathrm{C}\right)$ was maintained. Single pulses $(2.5 \mathrm{ml}$ ) of an amino acid mixture (Ala, His, Lys, Met, Phe, Trp, and Val, all from Sigma) were injected into the water inflow of the nursery every $30 \mathrm{~min}$ for the duration of the experiment (14 d). Each pulse exposed the larvae to a brief peak concentration of $1 \mu \mathrm{M}$ of each amino acid, and a 10,000-fold clearance of these amino acid stimuli occurred after $\sim 4$ min. In control experiments, water alone, without amino acids, was injected into the flow-through unit.

In vivo imaging of glomerular development. Beginning at $72 \mathrm{hpf}$, SAGFF27A;UAS:GFP larvae were imaged every second day for a maximum of $14 \mathrm{~d}$ according to a previously established protocol (Sato et al., 2005). Fish were anesthetized with $0.016 \%$ buffered tricaine (Nacalai Tesque) and placed in a small drop of 3\% methylcellulose (Sigma) in zebrafish Ringer's solution. The fish were carefully positioned with forceps and then covered with 2\% low melting-point agarose (Sigma) in zebrafish Ringer's solution. OBs were then imaged with a Fluoview FV500 confocal laser-scanning microscope (Olympus) at $1 \mu \mathrm{m}$ focal plane intervals to a maximum depth of $100 \mu \mathrm{m}$. Each larva was imaged from dorsal and left lateral aspects to obtain detailed images of GFPlabeled lateral glomeruli. After imaging, the larvae were carefully removed from the agarose and returned to the nursery unit.

Identification of glomeruli in transgenic larvae. In the OBs of SAGFF27A;UAS:GFP larvae, only a subset of OSN axons and their terminals were labeled with GFP. We identified glomeruli as approximately spherical structures that were encapsulated by fluorescent fibers that formed a visible and separate stalk connected to the olfactory nerve $(\mathrm{ON})$. To confirm that these criteria allowed us to identify glomeruli in a manner consistent with our other anatomical data, we processed brains from transgenic larvae for immunohistochemistry as described above, imaged them, and compared them with our in vivo data.

Statistics. Anatomical data obtained from our immunohistochemistry experiments were organized and pooled across animals according to identity of the glomerulus (e.g., lateral glomerulus $1 G_{3}$ ) or region in which the glomerulus was located (e.g., lateral glomerulus $1 G_{x}$ ), separately for each developmental stage. The data presented in this manuscript are mean $\pm \mathrm{SD}$, unless indicated otherwise. To compare numbers and sizes of glomeruli between different developmental stages we conducted ANOVA of developmental stage versus number or area of glomeruli. Data obtained from repeated in vivo imaging of the same larvae were similarly treated but compared via one-way ANOVA for repeated measures. All statistics were analyzed with SPSS software (Statistical Package for the Social Sciences). 

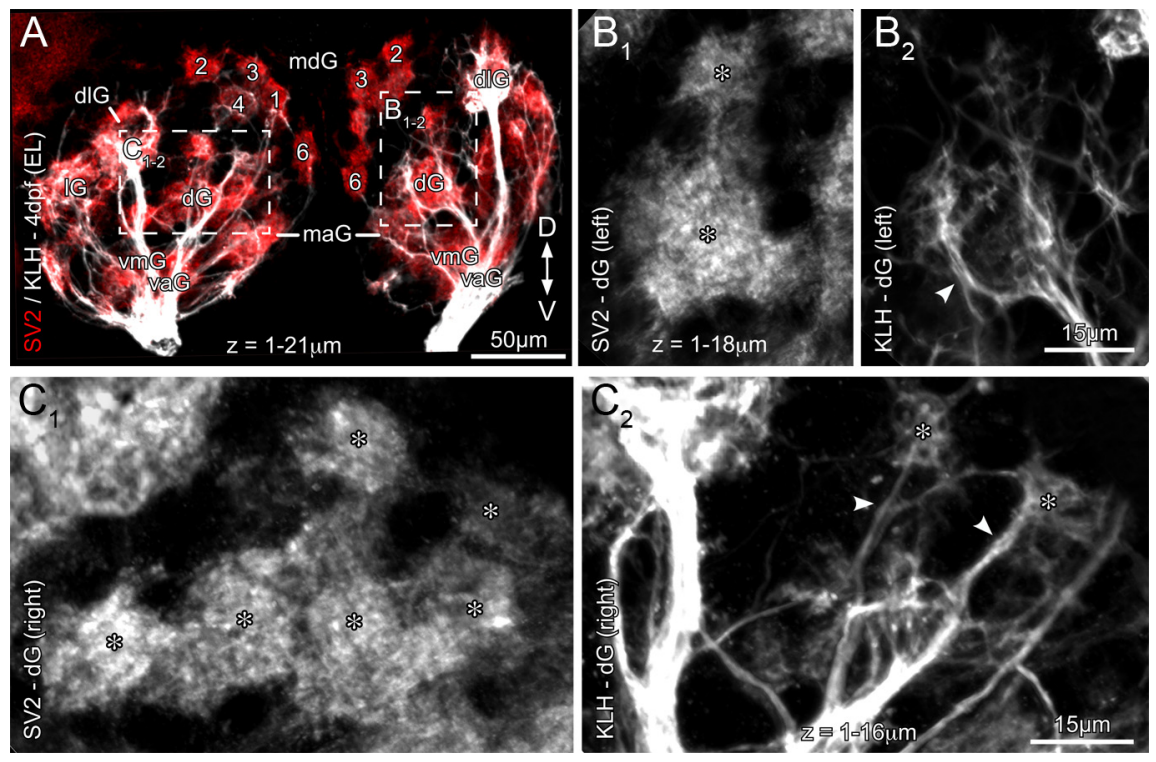

Figure 4. A, Maximum intensity confocal projection of a $4 \mathrm{dpf} O \mathrm{~B}$, viewed from a frontal perspective. $\mathbf{B 1}, \mathbf{B 2}, \mathbf{C 1}, \mathbf{C 2}$, Highmagnification views of anti-SV2 and anti-KLH labeling in the left and right OBs, respectively (as indicated in $\boldsymbol{A}$ ). *New glomeruli emerged in the $\mathrm{d} G$ region but varied in number and arrangement between $\mathrm{OBs}$ (compare $\boldsymbol{B} 1$ and $\mathbf{C}$ ); some of these glomeruli were innervated by anatomically distinct axon fascicles ( 2 , arrowheads). $\boldsymbol{B 2}$, $\mathbf{2}$, Scale bars also apply to $\boldsymbol{B} \mathbf{1}$ and $\mathbf{C 1}$. EL, Early larva; ML, mid-larva; JU, juvenile.

\section{Results}

Organization of the $\mathrm{OB}$ primordia in embryonic zebrafish

The OB primordia of $72 \mathrm{hpf}$ embryos occupied the anterior surface of the developing forebrain and were best visualized in frontal perspectives (Fig. 1). The primordia could be divided into seven regions, which were distinguishable based on anatomical and neurochemical features. Specifically, we detected the following: (1) a dorsal region of diffuse afferent terminals that would later contain the dorsal glomeruli (Fig. 1A1, dG); and (2) a dorsolateral region that would later contain the dorsolateral glomeruli (Fig. 1A2, dlG). The $\mathrm{dG}$ and $\mathrm{dlG}$ were comparatively large and irregularly shaped but reliably stained with the anti-calretinin and anti-G ${ }_{\alpha s / o l f}$ antibodies (compare Fig. $1 A 1, A 2$ with Fig. $1 B, C$ ); neither region contained discernible glomeruli. We also identified six mediodorsal glomeruli (Fig. $1 A 1, A 2, \mathrm{mdG}_{1-6}$ ), which were comparatively small and had roundish shapes characteristic of glomeruli. All mdG displayed reliable anti-SV2immunoreactivity (IR) (e.g., Fig. $1 B$ ), and the $\mathrm{mdG}_{2}$ and $\mathrm{mdG}_{5}$ were further distinguishable based on their innervation by S100-IR axons (Fig. $1 D$ ) and $\mathrm{G}_{\alpha \mathrm{o}}$-IR axons (Fig. $1 E$ ), respectively.

Ventrally, we detected a ventromedial region, which would later give rise to the ventromedial and ventroanterior glomeruli (Fig. $1 A 2$, vmG/vaG) and a separate, more anterior region, which would give rise to the medioanterior glomeruli (Fig. $1 A 1, \mathrm{maG}$ ). These regions were irregularly shaped, but always displayed calretinin and $\mathrm{G}_{\alpha \mathrm{s} / \mathrm{olf}} \mathrm{IR}$ (Fig. $1 C$ ). In the ventroposterior OBs, we detected a pair of approximately spherical ventroposterior glomeruli (vpG); these units did not exhibit labeling against $G$ protein subunits or calcium-binding proteins but were identifiable based on their roundish shapes and reliable anti-SV2-IR (Fig. 1A3,E, $\mathrm{vpG}_{1-2}$ ).

Finally, the lateral OB primordia contained two distinct glomeruli $\left(\mathrm{lG}_{3-4}\right)$ and a subregion of diffuse innervation, which would later give rise to additional lateral glomeruli, the $1 \mathrm{G}_{\mathrm{x}}$. All afferent axons projecting to these lateral structures displayed strong calretinin-IR (Fig. 1A2,A3). Thus, at the end of embryonic development (72 hpf), each $\mathrm{OB}$ contains 10 individually identifiable glomeruli and five regions of diffuse innervation (compare Dynes and Ngai, 1998; Koide et al., 2009) (Fig. 1F).

\section{Distinct mechanisms of postembryonic development among zebrafish glomeruli}

Growth but not multiplication of the $m d G$ The mdG were arranged in two approximately triangular groups in all stages of larval development (Fig. 2A-C), and we identified $5.0 \pm 0.9 \mathrm{mdG}$ per $\mathrm{OB}$ of early larvae (Fig. $2 A, B$ ) and $5.7 \pm 0.5 \mathrm{mdG}$ in each $\mathrm{OB}$ of juvenile zebrafish (Fig. 2C). The numbers of mdG did not appear to increase significantly during postembryonic development, but we observed a continuous and significant increase in their cross-sectional area $(p<0.0001 ;$ Fig. $2 D)$. We also asked whether the relative positions of the mdG remained consistent during postembryonic development. To answer this, we selectively labeled the $\mathrm{mdG}_{2}$ with the anti-S100 antibody and the $\mathrm{mdG}_{5}$ with the anti- $\mathrm{G}_{\alpha \mathrm{o}}$ antibody (Fig. $2 E-H)$. Using this strategy, we confirmed that the positions of these two glomeruli remained essentially unchanged: the $\mathrm{mdG}_{2}$ was always located on the dorsolateral edge of the $\mathrm{mdG}$ group (Figs. $1 F$ and $2 E, F$ ), whereas the $\mathrm{mdG}_{5}$ was always located ventrally, wedged between the larger $\mathrm{mdG}_{6}$ and other glomeruli of this cluster (Figs. $1 E$ and $2 G, H$ ). This is essentially the same arrangement as in the OBs of mature zebrafish (compare Braubach et al., 2012).

\section{Growth but not multiplication of the $v p G$}

The vpG also retained stable numbers and arrangements after their initial appearance in zebrafish embryos. After hatching, the vpG were consistently identifiable as paired spheroidal glomeruli, which were stereotypically positioned in the ventroposterior OBs and distinguishable from other ventral glomeruli (Fig. $3 A-C$ ). The numbers of vpG remained unchanged during larval development $(p=0.96$; Fig. $3 D)$, but both glomeruli displayed significant growth $(p<0.0001$; Fig. $3 D)$. Together with the $\mathrm{mdG}$, the vpG eventually comprised some of the largest glomeruli in juvenile zebrafish (e.g., Figs. $2 C$ and $3 C$ ), a finding that is consistent with observations in adult specimens (Braubach et al., 2012). The postembryonic maturation of the $\mathrm{mdG}$ and the $\mathrm{vpG}$ thus appears to consist mainly of growth of embryonically formed glomeruli; no units are added to or lost from either group.

\section{Compartmentalization of the $d G, d l G, m a G$, and $v m G / v a G$}

The calretinin and $\mathrm{G}_{\alpha \mathrm{s} / \mathrm{olf}}$ double-labeled glomeruli that occupied the dorsal and ventral OBs of embryonic zebrafish (i.e., Fig. $1 F$, $\mathrm{dG}, \mathrm{dlG}, \mathrm{maG}$, and vmG/vaG) reorganized shortly after hatching. For example, in $4 \mathrm{dpf}$ post-hatching larvae, putative presynaptic terminals (SV2 puncta) in the $\mathrm{dG}$ region became increasingly compartmentalized and formed distinct spheroidal aggregates (Fig. $4 B 1, C 1$, asterisks). The axons entering the $\mathrm{dG}$ also began to form distinct stalks and selectively targeted individual aggregates of SV2-IR puncta (Fig. 4C2, asterisks). Because aggregates of presynaptic proteins and/or selective axonal innervation are typical of glomeruli (e.g., Manzini et al., 2007; Koide et al., 2009), we 
interpret our findings as a partitioning of the embryonic $\mathrm{dG}$ region into new glomeruli, the $\mathrm{dG}_{\mathrm{x}}$. Indeed, the emergent $\mathrm{dG}_{\mathrm{x}}$ corresponded approximately in total cross-sectional area to that of the embryonic $\mathrm{dG}$ region identified before hatching (i.e., Fig. $1 A 1, \mathrm{dG}$ ): the area that was occupied by the embryonic $\mathrm{dG}(472.8 \pm 78.5$ $\mu \mathrm{m}^{2}$ per bulb) was replaced with $6.6 \pm 1.7$ individual $\mathrm{dG}_{\mathrm{x}}$ after hatching; these $\mathrm{dG}_{\mathrm{x}}$ had a combined cross-sectional area of $540.0 \pm 49.2 \mu \mathrm{m}^{2}$ per OB (Fig. $5 A$ ).

In $3 \mathrm{D}$ reconstructions of larval OBs, each $d_{\mathrm{x}_{\mathrm{x}}}$ was clearly visible as a separate spheroidal structure (Fig. $5 E 1, \mathrm{dG}_{\mathrm{x}}$ ); these same structures were also detectable in individual optical sections as anatomically distinct, round aggregates of SV2-IR puncta (e.g., compare $\mathrm{dG}_{\mathrm{x} 1}$ in Fig. 5E1,E3). We made similar observations with respect to two additional regions, the dlG and $\mathrm{maG}$, as summarized in Figure 5B, C. For brevity, these observations will not be presented in detail.

The development of calretinin and $\mathrm{G}_{\alpha \mathrm{s} / \mathrm{olf}}$ double-labeled glomeruli proceeded with conspicuous anatomical variations within and between individual larvae. Figure 6 shows a group of small ventromedial glomeruli, the $\mathrm{vmG}_{\mathrm{y}}$, at three stages of larval development. Initially, these glomeruli consisted of singular, bilaterally symmetric structures (Fig. $6 A 2, A 3, \mathrm{vmG})$. Beginning $\sim 1$ week after hatching, however, these vmG progressively divided into multiple $v G_{y}$, each distinctly innervated by separate axon fascicles (Fig. 6B2, arrows) that ended in roundish aggregates of axon terminals (Fig. 6B2, asterisks). Anatomical variations were common among the $\mathrm{vmG}_{\mathrm{y}}$. In the specimen shown in Figure 6B, for example, we identified multiple $\mathrm{vmG}_{\mathrm{y}}$ in the left $\mathrm{OB}$ (Fig. 6B2, asterisks), whereas only 1 or $2 \mathrm{vmG}_{\mathrm{y}}$ appeared to have differentiated in the right $\mathrm{OB}$ (Fig. 6B3, asterisks). Indeed, variations persisted into the juvenile stage, so that we typically observed different numbers of $\mathrm{vmG}_{\mathrm{y}}$ in different $\mathrm{OBs}$, both within (e.g., Fig. 6C1-C3) and between specimens (data not shown); furthermore, this is consistent with observations in adult zebrafish (Braubach et al., 2012). Thus, calretinin-IR and $G_{\alpha s / o l f}$ IR glomeruli develop mainly after hatching via a process of division of embryonically formed precursors; this process proceeds with conspicuous variations in glomerular numbers and distributions.

\section{Lateral glomeruli ( $l G)$ mature via two mechanisms}

In preceding sections, we described two distinct mechanisms of postembryonic development for glomeruli in different $\mathrm{OB}$ regions. Both of these mechanisms appeared to occur among the $1 G$, which were first visible in embryonic zebrafish. Specifically, the $\mathrm{lG}_{3}$ and $\mathrm{lG}_{4}$ were identifiable in $72 \mathrm{hpf}$ embryos as two compact glomeruli that were connected via separate axon stalks to the
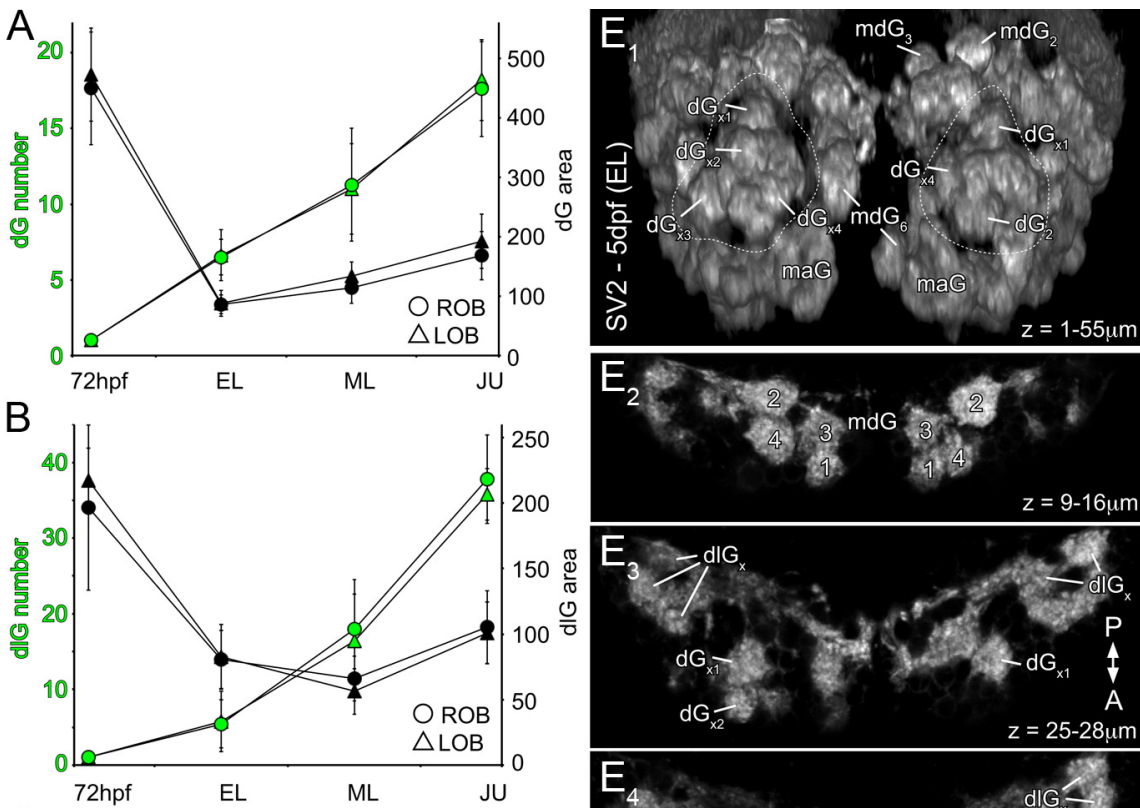

A-C, The cross-sectional area (black) of calretinin and $G_{\text {as/of }}$ double IR glomerular regions decreases after hatching E1-E6. E2-E6, ${ }^{*}$ Glomeruli that are not visible in the 3D reconstruction. Scale bar in E6 applies to all other panels in the column. EL, Early larva; ML, mid-larva; JU, juvenile; LOB and ROB, left and right $0 B$.

$\mathrm{ON}$ (Fig. 7A1). After hatching, the $\mathrm{lG}_{3}$ and $\mathrm{lG}_{4}$ remained visible from dorsal (Fig. 7B1) and lateral perspectives (Fig. 7C1,D1), and we were able to identify these two glomeruli, without exception, throughout larval development (Fig. $7 E$ ). The cross-sectional areas of $\mathrm{lG}_{3}$ and $1 \mathrm{G}_{4}$ increased during larval development $(p<$ 0.0001 ; Fig. $7 E$ ), and they eventually comprised some of the largest and most distinctive glomeruli in the OBs of juvenile zebrafish.

In contrast, the $\mathrm{lG}_{\mathrm{x}}$ developed after hatching, apparently via segregation from a common precursor region, first visible in 72 hpf embryos between $\mathrm{lG}_{3}$ and $\mathrm{lG}_{4}$ (Fig. $7 A 1-A 4, \mathrm{lG}_{\mathrm{x}}$ ). Immediately after hatching, the cross-sectional area of the $\mathrm{lG}_{\mathrm{x}}$ precursor decreased (Fig. $7 F$ ) and several smaller $\mathrm{lG}_{\mathrm{x}}$ appeared in its place (e.g., Fig. $7 B 2, C 2, \mathrm{G}_{\mathrm{x}}$ ). The average cross-sectional area of newly formed $\mathrm{lG}_{\mathrm{x}}\left(67.9 \pm 23.2 \mu \mathrm{m}^{2}\right)$ was significantly smaller than that 

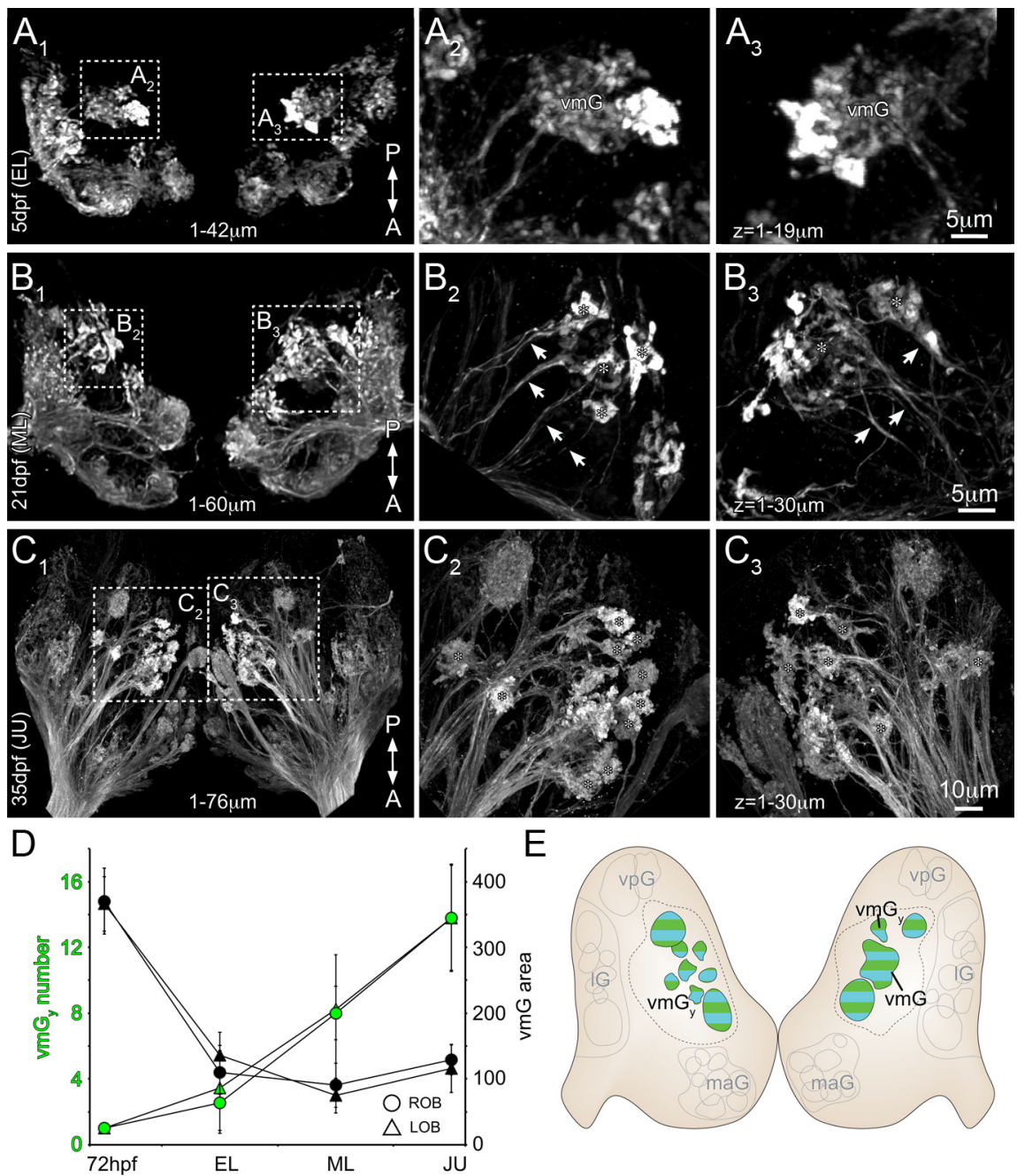

E

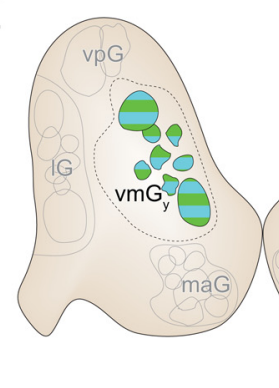

Figure 6. Maximum intensity confocal projections showing anti-calretinin-stained OBs of an early larva (EL;A1), mid-larva (ML; B1), and juvenile (JU; C1) zebrafish. High-magnification confocal projections of the vmG in left and right $0 B$ s are shown to the right of each specimen (indicated with dashed rectangles in left panels). The $\mathrm{vmG}_{\mathrm{y}}$ of $E \mathrm{~L}$ consist of a single, bilaterally symmetric vmG region (A1-A3); this region is replaced by multiple anatomically distinct $\mathrm{vmG}_{y}$ in $\mathrm{ML}(\boldsymbol{B} \mathbf{1}-\boldsymbol{B} \mathbf{B})$ and JU (C1-C3). D, The plot shows the number (green) and size (black) of $\mathrm{vmG}_{\mathrm{y}}$ per OB throughout embryonic and larval development. Data are mean \pm SD; numbers from 5 animals per developmental stage. $\boldsymbol{E}$, The schematic illustrates the approximate location of the $\mathrm{vmG}_{\mathrm{y}}$ with respect to other glomeruli in ML. Scale bars in the right panels apply to other panels in each row. EL, Early larva; ML, mid-larva; JU, juvenile; LOB and $\mathrm{ROB}$, left and right $\mathrm{OB}$.

of the $1 G_{x}$ precursor $\left(99.3 \pm 6.9 \mu \mathrm{m}^{2} ; p<0.05\right.$, ANOVA), suggesting that $l G_{x}$ may have formed as a result of $l_{\mathrm{x}}$ precursor reorganization. These data indicate two distinct maturation mechanisms among the lateral glomeruli; the $1 \mathrm{G}_{3}$ and $\mathrm{lG}_{4}$ remain unchanged in number but display significant growth, whereas the smaller $1 G_{x}$ proliferate.

Olfactory enrichment alters the development of small $\mathbf{l G}_{\mathbf{x}}$ The development of glomeruli described thus far occurred in larvae reared in standard conditions. We next examined whether olfactory enrichment would affect the development of certain amino acid-responsive lG. For this purpose, we exposed larval zebrafish to amino acid-enriched versus control olfactory environments and analyzed the development of lateral glomeruli in vivo. As enrichment stimulus, we chose an amino acid mixture that evokes neural activity in the $\mathrm{lG}_{3}$ and $\mathrm{lG}_{\mathrm{x}}$, but not the $\mathrm{lG}_{4}$ (T.K., unpublished observation). All of these glomeruli were readily visible in SAGFF27A;UAS:GFP double-transgenic ze-

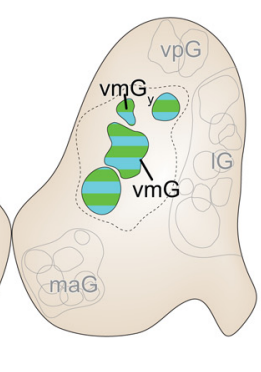

brafish via fluorescence microscopy (Fig. 8). Specifically, the $\mathrm{lG}_{3-4}$, and several smaller $\mathrm{lG}_{\mathrm{x}}$ beneath and between them, were labeled by the SAGFF27A;UAS:GFP transgene (Fig. 8A1-A3). The GFP labeling overlapped fully with calretinin-IR (compare Fig. 8A1-A3 with Fig. 8B1-B3) and SV2-IR (Fig. 8C1-C3), confirming that the SAGFF27A;UAS:GFP transgene labels the same lateral glomeruli as described above. Imaged in vivo, the $\mathrm{lG}_{3-4}$ were identifiable as brightly labeled glomeruli located near the lateral OB surface (Fig. 8E1); the $\mathrm{lG}_{\mathrm{x}}$ were visible below the $\mathrm{OB}$ surface and were often difficult to discern, given their uniform labeling and diffuse innervation (Fig. 8E2).

The $\mathrm{IG}_{3}$ of SAGFF27A;UAS:GFP larvae reared in amino acid-enriched versus control environments $(n=8$ for both groups) developed almost identically to one another. Without exception, we identified $1.0 \pm 0.0 \mathrm{lG}_{3}$ in animals of both groups between $72 \mathrm{hpf}$ and $14 \mathrm{dpf}$. In both groups, the $\mathrm{lG}_{3}$ remained visible in essentially the same configuration as shown in a series of data obtained from repeatedly imaged larvae in each experimental condition (Fig. 9A1-A6,B1-B6). Furthermore, the size of the $\mathrm{lG}_{3}$ in experimental larvae exposed to olfactory enrichment did not differ from controls at any time during our experiment (Fig. 9C: $p=0.441$ in repeated-measures ANOVA). The $\mathrm{lG}_{4}$ glomerulus, which is unresponsive to the amino acid enrichment stimulus, also displayed no difference in development between control and experimental conditions (Fig. $9 D: p=0.473$ ).

The OSN innervation of targets beneath the $\mathrm{IG}_{3-4}$ was disorganized and lacked glomerular features in $72 \mathrm{hpf}$ specimens (Fig. 10A1,B1). However, in the control larva shown in Figure 10A1$A 6$, we identified a small spheroidal glomerulus with a visible connection to the $\mathrm{ON}$ beginning at 9 $\operatorname{dpf}\left(\right.$ Fig. $10 A 4, \mathrm{G}_{\mathrm{x} 1}$ ). This unit remained visible at $11 \mathrm{dpf}$ (Fig. $\left.10 A 5,1 \mathrm{G}_{\mathrm{x} 1}\right)$, but was difficult to discern at a later developmental stage (Fig. 10A6, $1 G_{x 1}$ ). The remaining lateral neuropil was diffusely organized, and we could not unambiguously identify developing glomeruli in the specimen shown. Overall, however, we observed a significant increase in the number of putative $1 G_{x}$ from $72 \mathrm{hpf}\left(0.8 \pm 0.4 \mathrm{lG}_{\mathrm{x}}\right)$ to $14 \mathrm{dpf}$ control larvae $\left(3.8 \pm 1.2 \mathrm{lG}_{\mathrm{x}} ; p<0.001\right.$ in repeated-measures ANOVA; $n=$ 8 ); these numbers correspond well with our other anatomical data.

In contrast, the development of the $\mathrm{lG}_{\mathrm{x}}$ was visibly and significantly altered in the amino acid-enriched condition. In the animal shown in Figure 10B1-B6, we could identify the first $\mathrm{lG}_{\mathrm{x}}$ already at $7 \mathrm{dpf}$, as distinct spheroidal structures that were connected to the ON (Fig. 10B3, $1 \mathrm{G}_{\mathrm{x} 1}$ and $\mathrm{lG}_{\mathrm{x} 2}$ ). These units persisted and appeared to grow, whereas additional glomeruli (i.e., $\mathrm{l}_{\mathrm{x} 3}$ ) appeared nearby (Fig. 10B4-B6). Indeed, a statistical analysis 
confirmed that, beginning at $7 \mathrm{dpf}$, significantly more $\mathrm{lG}_{\mathrm{x}}$ were identifiable in experimental larvae than in control animals from the same clutch (Fig. 10C; $p<0.05$, repeated-measures ANOVA). Furthermore, individual $\mathrm{lG}_{\mathrm{x}}$ in experimental larvae were smaller than those in control larvae, again beginning at $7 \mathrm{dpf}$ and persisting throughout the remainder of the observation period (14 dpf; Fig. 10D; $p<$ 0.05 , repeated-measures ANOVA).

Finally, we counted the number of OSNs for each group and developmental stage. Our data indicate that the number of OSNs increased significantly in both groups $(p<0.001$, repeatedmeasures ANOVA), but we did not observe a difference in the number of OSNs in control and experimental animals (Fig. 10E; $p=0.670$, repeated-measures ANOVA). Thus, rearing zebrafish larvae in an amino acid-enriched odor environment appears to alter the maturation of small lateral glomeruli, the $\mathrm{lG}_{\mathrm{x}}$, without affecting survival or proliferation of OSNs.

\section{Discussion}

We have built on a previous anatomical study (Braubach et al., 2012) to undertake an analysis of the development and maturation of zebrafish olfactory glomeruli. Our findings are consistent with previous descriptions of glomeruli in zebrafish embryos (Dynes and Ngai, 1998; Li et al., 2005; Koide et al., 2009), larvae (Li et al., 2005), and adults (Baier and Korsching, 1994; Braubach et al., 2012). Furthermore, we identified distinct maturation mechanisms among zebrafish glomeruli. Large glomeruli, which were labeled selectively with antibodies against certain G-protein subunits or calcium-binding proteins, emerged during embryonic development and persisted in stable configurations afterward. Small glomeruli, which displayed labeling against $\mathrm{G}_{\text {olf }}$ and/or calretinin, segregated from larger precursors after hatching and proliferated with conspicuous variation in number and distribution, presumably influenced by sensory input. Our results add to a growing literature describing similarly distinct mechanisms of $\mathrm{OB}$ development in other vertebrate species.

\section{Early development of glomeruli}

Glomeruli are stereotypically arranged in distinct regions of the mature zebrafish OB (Braubach et al., 2012). These regions are innervated by specific OSN types (Sato et al., 2005; Gayoso et al., 2011) and are selectively activated by particular chemostimulants (Friedrich and Korsching, 1997, 1998). We demonstrate that the coarse regional layout and neurochemistry of zebrafish glomeruli already resemble their mature configuration as early as at $72 \mathrm{hpf}$, confirming that the patterning of these structures begins during embryonic development, when external cues are limited. From
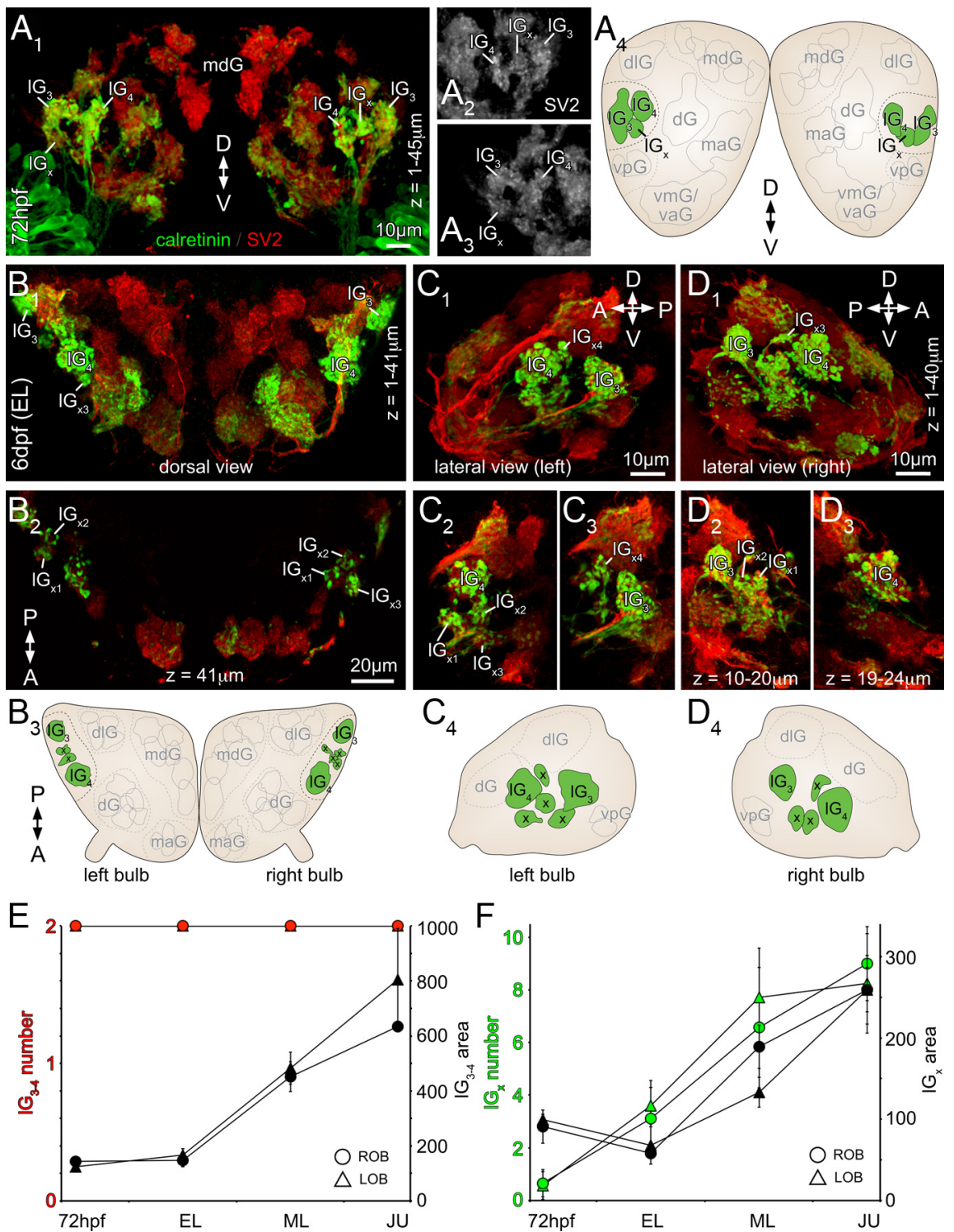

Figure 7. Maximum intensity confocal projections and diagrams of $O B s$ in a zebrafish embryo (A1-A4), and dorsal (B1-B3) and lateral (C1-D4) OBs from a single $6 \mathrm{dpf}$ larva. All specimens were stained with anti-calretinin (green) and anti-SV2 (red and gray). The $1 \mathrm{G}_{3-4}$ are visible at $72 \mathrm{hpf}(\boldsymbol{A 1}-\boldsymbol{A 4})$ and remain present throughout subsequent developmental stages $(\boldsymbol{B 1}, \mathbf{C 1}, \mathbf{D 1})$. The $I G_{x}$ develop after hatching via a small $I G_{x}$ precursor $(\boldsymbol{A 4})$. The numbers of newly formed $I G_{x}$ differed between $0 B$ s (compare $C 4$ and D4). $\boldsymbol{A 2}, \mathbf{A 3}$, SV2 labeling of the $\mathrm{G}$, in the same specimen as shown in $\boldsymbol{A} 1 . \boldsymbol{E}, \boldsymbol{F}$, Data plots showing the numbers (red and green) and stage. Scale bar in $\boldsymbol{A 1}$ applies to $\mathbf{A 2}, \mathbf{A 3}$; scale bar in $\mathbf{B 2}$ applies to $\mathbf{B 1}$; and scale bars in $\mathbf{C}$ and $\mathbf{D 1}$ apply to $\mathbf{C 2}-\mathbf{C}$ and $\mathbf{D 2}-\mathbf{D 3}$, respectively. EL, Early larva; ML, mid-larva; JU, juvenile; LOB and ROB, left and right $\mathrm{OB}$.

36 hpf onwards, OSN axons fasciculate, enter the OB, and target individual glomeruli without displaying directional changes or pauses (Dynes and Ngai, 1998). This targeted axonal migration is dependent on the presence of pioneer axons (Whitlock and Westerfield, 1998), which require functional Slit/Robo2 (Miyasaka et al., 2005) and chemokine signaling (Miyasaka et al., 2007) to fasciculate properly and extend into the $\mathrm{OB}$ primordia. Compromising the expression of Slit/Robo and other guidance molecules, such as anosmin-1 and netrin/DCC (Yanicostas et al., 2009; Madelaine et al., 2011; Lakhina et al., 2012), perturbs OSN axon targeting and leads to the formation of disorganized and incomplete glomerular arrays. Interestingly, the Robo2 mutant astray (Miyasaka et al., 2005) appears to display more severe developmental deficits in some glomeruli $\left(\mathrm{lG}_{4}\right)$ than in 

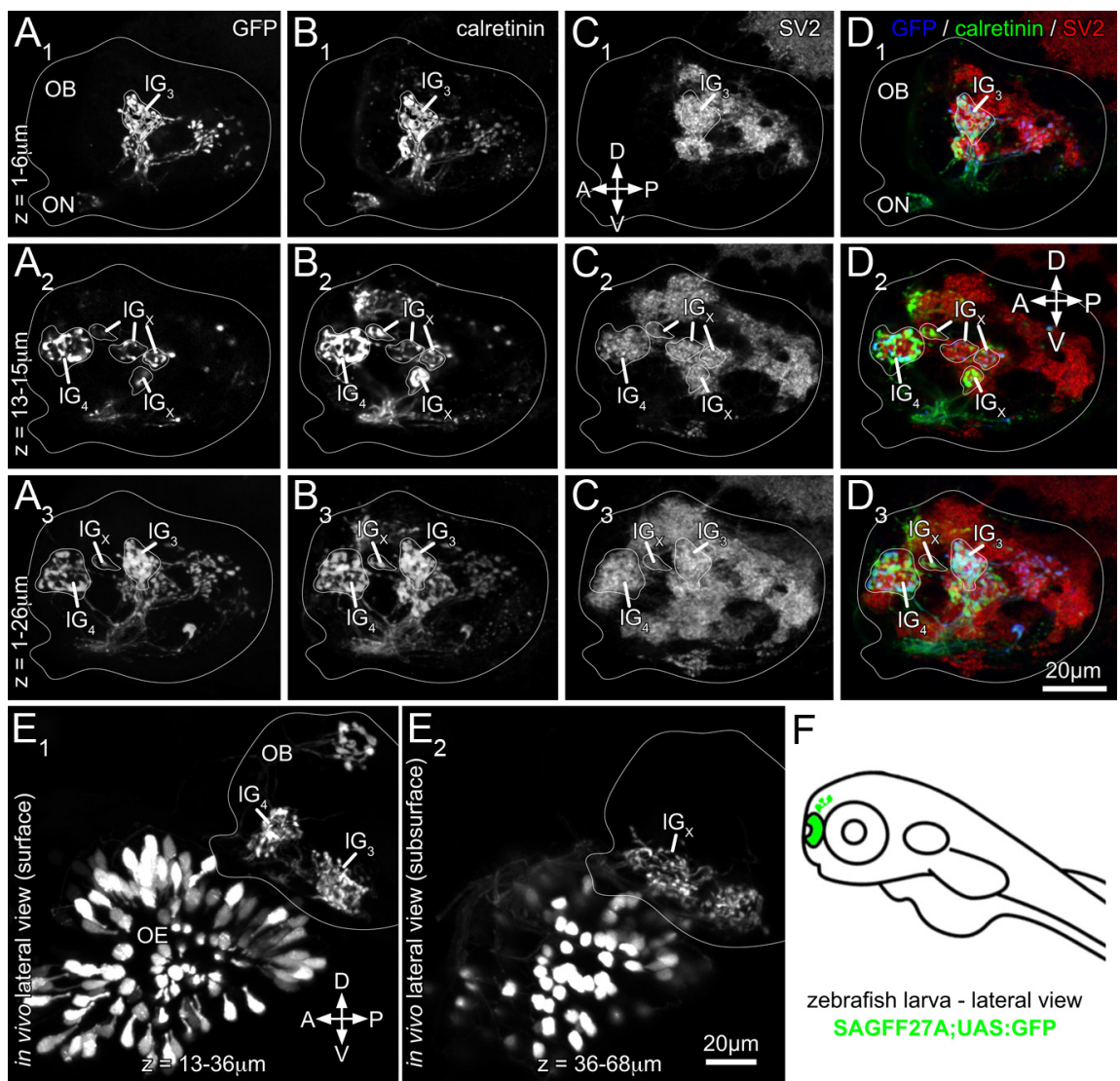

zebrafish larva - lateral view SAGFF27A;UAS:GFP

Figure 8. Maximum intensity confocal projections showing the left lateral OB of an $11 \mathrm{dpf}$ SAGFF27A;UAS:GFP transgenic zebrafish larva, counterstained with markers for $I G$ and oriented in the same manner as representative morphological data presented in this article. A1-A3, The $\mathrm{IG}_{3-4}$ and the $\mathrm{IG}_{\mathrm{x}}$ are clearly labeled by GFP in the SAGFF27A;UAS:GFP transgenic zebrafish, and the GFP overlaps fully with calretinin-IR (B1-B3) and SV2-IR (C1-C3). E1, E2, A left lateral OB of a live 9 dpf SAGFF27A;UAS:GFP larva imaged with a confocal microscope. The olfactory epithelium (OE) contains multiple brightly stained cells, which project axons to glomeruli in superficial (E1) and deep regions $(E 2)$ of the lateral $O B$. $F$, The schematic indicates the orientation of the imaged region with respect to a zebrafish larva. The scale bar in D3 applies to panels A1-D3; scale bar in E2 applies to E1.

others $\left(\mathrm{lG}_{3}\right)$, suggesting that the development of individual glomeruli may be specifically linked to certain guidance mechanisms. Additional guidance mechanisms (e.g., Stevens and Halloran, 2005) and odorant receptor-mediated convergence of OSN axons into discrete glomeruli (Mombaerts, 2006; Sakano, 2010) may further contribute to the initial assembly of zebrafish glomeruli. Further identification of such processes may be facilitated by the high-resolution anatomical maps provided in our study.

\section{Distinct modes of glomerular maturation}

Despite maintained similarities in regional OB organization throughout ontogeny, all glomeruli display significant anatomical reorganization after hatching. Early formed glomeruli, such as the $\mathrm{lG}_{3-4}$, mdG, and vpG, displayed consistent and significant growth. This growth presumably occurred as new OSN axons and processes from local bulbar neurons (MackBucher et al., 2007) invaded the glomeruli and may further correlate with their functional development. Certain units in the $1 \mathrm{G}$ and $\mathrm{mdG}$ groups, for example, appear to respond to alarm pheromone contained in skin extract (Mathuru et al., 2012; T.K., unpublished observations). However, behavioral responses to alarm pheromone do not emerge until $\sim 50 \mathrm{dpf}$
(Waldman, 1982), long after the first appearance of discrete glomeruli in the $\mathrm{lG}, \mathrm{mdG}$, and other regions. Certain glomeruli may therefore not be fully functional during early development, and acquisition of functionality could correlate with, and critically depend upon, postembryonic glomerular maturation.

A distinct glomerular maturation process occurred among the $G_{\text {olf }}$ and/or calretinin-labeled dG, dlG, $\mathrm{maG}, \mathrm{vmG}_{\mathrm{y}}$, and $1 G_{x}$. At the time of hatching, these regions resembled their adult counterparts in terms of overall position and immunoreactivity, but only a fraction of glomeruli known from adults could be identified. However, a large proportion of odorant receptor genes may already be expressed when larvae hatch (Argo et al., 2003). We therefore hypothesize the following: (1) there may be significant overlap and nonspecific targeting of molecularly dissimilar OSN axon types in the aforementioned glomerular precursors; and (2) after hatching, OSN axons reorganize, with molecularly similar axons increasingly fasciculating and becoming restricted to appropriate glomeruli. This would then be paralleled by (3) a significant decrease in the size of the glomerular precursor, as a consequence of (4) its segregation into multiple smaller daughter glomeruli. Our observations are consistent with data from mice, in which the number of discernible glomeruli increases fourfold to fivefold between birth and sexual maturity (Pomeroy et al., 1990), paralleled by progressively changing odor-evoked glomerular ensemble activity (Greer et al., 1982). Both of these processes presumably occur as diffusely targeted OSN axons increasingly coalesce to form anatomically and molecularly discrete glomeruli (Conzelmann et al., 2001; Potter et al., 2001).

Following their initial proliferation in early larvae, we observed that the number of glomeruli in the $\mathrm{dG}, \mathrm{dlG}, \mathrm{maG}, \mathrm{vmG}_{\mathrm{y}}$ and $\mathrm{lG}_{\mathrm{x}}$ regions continued to increase throughout larval development. These increases did not correlate with reductions in glomerular cross-sectional areas, as might have been expected with further anatomical segregation/refinement of precursor structures. Such analyses might be complicated by large increases in OSN numbers, but it is also possible that new glomeruli form de novo from new populations of OSN axons. This possibility may be addressed with zebrafish that permit visualization of individual OSN axon types (Lakhina et al., 2012), and similar strategies have already proven valuable in studying rodent $\mathrm{OB}$ development (Potter et al., 2001; Feinstein and Mombaerts, 2004; Zou et al., 2004). To summarize, the zebrafish glomerular map develops in two stages: (1) a coarse positional map that includes early emerging large glomeruli forms during embryonic development; and (2) this coarse map is progressively refined during 5 weeks of larval development to produce an array of discrete glomeruli that closely resemble their adult counterparts in number and distribution. A similar sequential process appears to be characteristic 
of olfactory system development in mice (Imai and Sakano, 2011).

\section{Activity-dependent maturation of small glomeruli}

The development of glomeruli in the dG, $\mathrm{dlG}, \mathrm{maG}, \mathrm{vmG}_{\mathrm{y}}$, and $\mathrm{lG}_{\mathrm{x}}$ regions proceeds with conspicuous variation in numbers and distributions. Furthermore, we demonstrated that larvae reared with olfactory enrichment developed more and significantly smaller $\mathrm{lG}_{\mathrm{x}}$ than control larvae, apparently without altered OSN proliferation. Thus, the maturation of certain small glomeruli appears to be influenced by sensory input.

To our knowledge, there is no prior study on activity-dependent developmental mechanisms in the zebrafish olfactory system. However, related observations in mice have established certain principles that may be relevant to other vertebrates. For example, behavioral conditioning during postnatal development of mice accelerated the refinement of particular glomeruli without affecting the proliferation of OSNs (Kerr and Belluscio, 2006). In contrast, olfactory deprivation (Zou et al., 2004) and perturbation of signaling mechanisms in OSNs impaired glomerular refinement (Zheng et al., 2000; Yu et al., 2004). The cellular mechanisms underlying these observations may not involve Hebbian plasticity because blockade of neurotransmission in OSNs innervating glomeruli by transgenic expression of tetanus toxin has little effect on the assembly of glomeruli in mice (Yu et al., 2004) and zebrafish (Koide et al., 2009). Instead, neural activity appears to regulate the expression of cell adhesion and sorting molecules on ingrowing OSN axons, which presumably fasciculate and/or defasciculate because of activity-driven expression of complementary cell attraction and repulsion molecules (Imai et al., 2006; Kaneko-Goto et al., 2008; Imai and Sakano, 2011). It remains to be seen whether such mechanisms operate in zebrafish, and our results may provide a useful framework for investigating this possibility.

Finally, it is interesting to consider current results suggesting that the patterning of certain glomeruli may be less susceptible to environmental influences than that of others. Specifically, a remarkable stereotypy in the number and distribution of large glomeruli has now been documented for zebrafish across all developmental stages (Baier and Korsching, 1994; Dynes and Ngai, 1998; Braubach et al., 2012). Furthermore, we showed that certain glomeruli $\left(\mathrm{G}_{3}\right)$ may not be affected by olfactory enrichment, whereas nearby units $\left(\mathrm{l}_{\mathrm{x}}\right)$ were clearly affected by the enrichment. Similarly, anosmic mice that are deficient in the olfactory cyclic nucleotidegated channel subunit 1 (ONC-1) gene develop abnormal M72 glomeruli, whereas their P2 glomeruli appear to develop normally
(Zheng et al., 2000). These findings indicate that the proper development and maturation of certain types of glomeruli may be less susceptible and/or differentially dependent on environmental influences.

In conclusion, zebrafish olfactory glomeruli exist as several different types, distinguishable on the basis of their anatomy and neurochemistry (Gayoso et al., 2011; Braubach et al., 2012), molecular makeup (Sato et al., 2005), physiology (Friedrich and Korsching, 1998), and outputs (Miyasaka et al., 2009). We have provided a uniquely comprehensive description of the developing zebrafish $\mathrm{OB}$ and show that distinct types of glomeruli form at different times, display distinct maturation mechanisms, and 


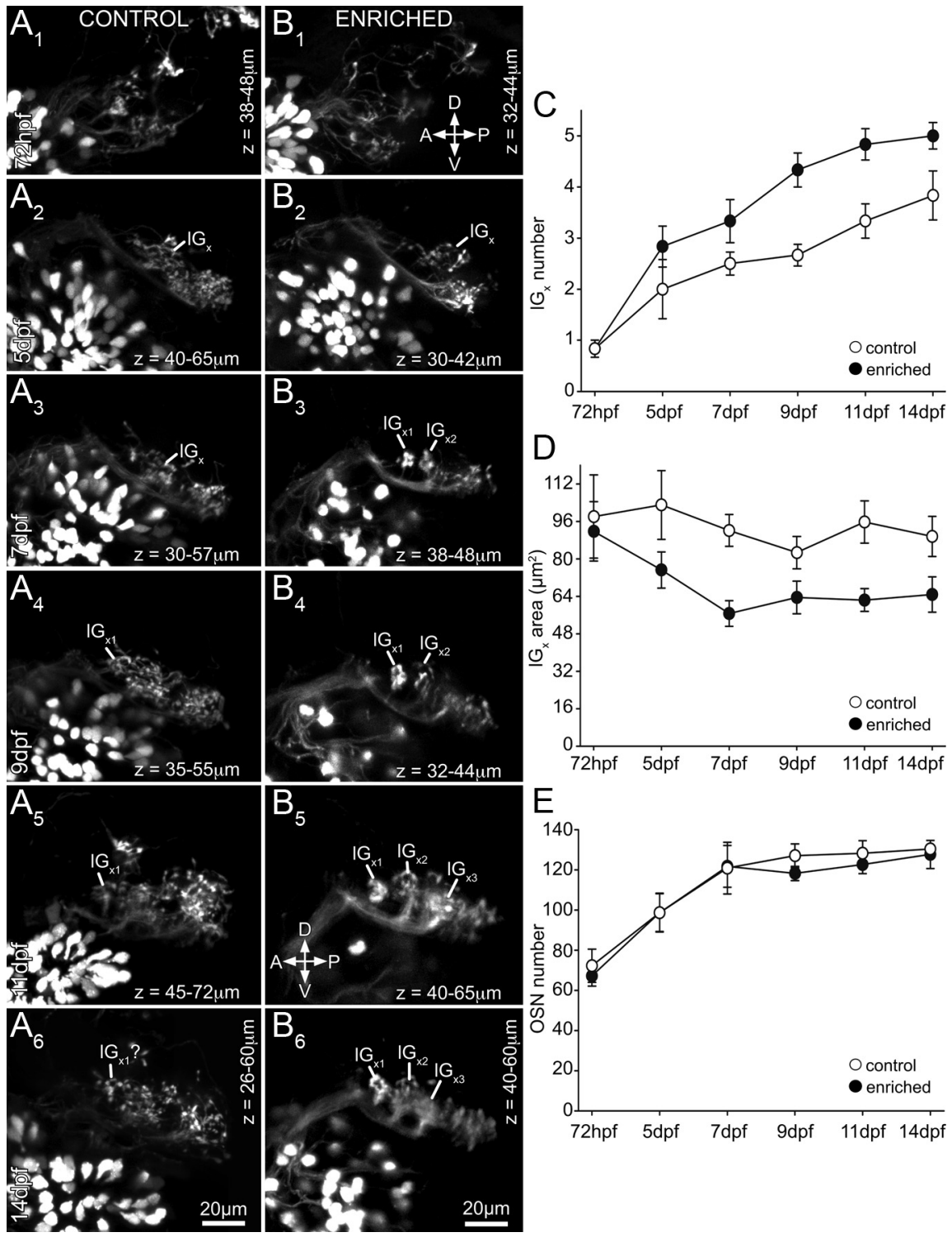

Figure 10. Effects of olfactory enrichment on the development of lateral glomeruli IG in SAGFF27A;UAS:GFP transgenic larvae, revealed via repeated in vivo imaging every second day from $72 \mathrm{hpf}(\boldsymbol{A} \mathbf{1}, \boldsymbol{B} \mathbf{)})$ to $14 \mathrm{dpf}(\boldsymbol{A} \mathbf{6}, \boldsymbol{B} \mathbf{6})$. Images are confocal projections depicting the left lateral $O B$ from a control larva $(\boldsymbol{A 1}-\mathbf{A 6})$ and a larva reared in an enriched olfactory environment (B1-B6). GFP-labeled fibers are initially disorganized $(\boldsymbol{A} \mathbf{1}, \boldsymbol{B} \mathbf{1})$ but give rise to individually identifiable $I \mathrm{G}_{\mathrm{x}}$ at various times after hatching (e.g., see $A 4, B 3$ ). The $I G_{x}$ are particularly easy to identify in experimental larvae and remain visible throughout the duration of the experiment $(\boldsymbol{B} 3-\boldsymbol{B} 6)$. C The rate of $I \mathrm{G}_{\mathrm{x}}$ development was significantly increased in experimental larvae, beginning at $7 \mathrm{dpf}$; the size of $\mathrm{IG}_{x}$ was significantly smaller in the experimental group, again beginning at $7 \mathrm{dpf}(\boldsymbol{D})$. $\boldsymbol{E}$, The number of $0 \mathrm{SN}$ and the rate of their development did not differ between control and experimental larvae at any time during the experiment. Plots represent mean \pm SD; $n=8$ in each condition. Scale bars in $\mathbf{A}$ and $\mathbf{B} \mathbf{6}$ apply to all other panels in each column.

develop via distinct cellular mechanisms that may depend differently on environmental inputs. It will be of interest now to resolve the molecular, cellular, and behavioral phenomena responsible for, and resulting from, these maturation processes.

\section{References}

Argo S, Weth F, Korsching SI (2003) Analysis of penetrance and expressivity during ontogenesis supports a stochastic choice of zebrafish odorant receptors from predetermined groups of receptor genes. Eur J Neurosci 17:833-843. CrossRef Medline

Asakawa K, Suster ML, Mizusawa K, Nagayoshi S, Kotani T, Urasaki A, Kishimoto Y, Hibi M, Kawakami K (2008) Genetic dissection of neural circuits by Tol 2 transposon-mediated Gal 4 gene and enhancer trapping in zebrafish. Proc Natl Acad Sci U S A 105:1255-1260. CrossRef Medline

Baier H, Korsching S (1994) Olfactory glomeruli in the zebrafish form an invariant pattern and are identifiable across animals. J Neurosci 14:219-230. Medline

Braubach OR, Fine A, Croll RP (2012) Distribution and functional organization of glomeruli in the olfactory bulbs of zebrafish (Danio rerio). J Comp Neurol 520:2317-2339. CrossRef Medline

Conzelmann S, Malun D, Breer H, Strotmann J (2001) Brain targeting and glomerulus formation of two olfactory neuron populations expressing related receptor types. Eur J Neurosci 14:1623-1632. CrossRef Medline

Dynes JL, Ngai J (1998) Pathfinding of olfactory neuron axons to stereotyped glomerular targets revealed by dynamic imaging in living zebrafish embryos. Neuron 20:1081-1091. CrossRef Medline

Feinstein P, Mombaerts P (2004) A contextual model for axonal sorting into glomeruli in the mouse olfactory system. Cell 117:817831. CrossRef Medline

Friedrich RW, Korsching SI (1998) Chemotopic, combinatorial, and noncombinatorial odorant representations in the olfactory bulb revealed using a voltage-sensitive axon tracer. J Neurosci 18:9977-9988. Medline

Friedrich RW, Korsching SI (1997) Combinatorial and chemotopic odorant coding in the zebrafish olfactory bulb visualized by optical imaging. Neuron 18:737-752. CrossRef Medline

Gaudin A, Gascuel J (2005) 3D atlas describing the ontogenic evolution of the primary olfactory projections in the olfactory bulb of Xenopus laevis. J Comp Neurol 489:403-424. CrossRef Medline

Gayoso JÁ, Castro A, Anadón R, Manso M (2011) Differential bulbar and extrabulbar projections of diverse olfactory receptor neuron populations in the adult zebrafish (Danio rerio). J Comp Neurol 519:247-276. CrossRef Medline

Greer CA, Stewart WB, Teicher MH, Shepherd GM (1982) Functional development of the olfactory bulb and a unique glomerular complex in the neonatal rat. J Neurosci 2:17441759. Medline

Hansen A, Zeiske E (1993) Development of the olfactory organ in the zebrafish, Brachydanio rerio. J Comp Neurol 333:289-300. CrossRef Medline

Imai T, Sakano H (2011) Axon-axon interactions in neuronal circuit assembly: lessons from olfactory map formation. Eur J Neurosci 34:1647-1654. CrossRef Medline

Imai T, Suzuki M, Sakano H (2006) Odorant receptor-derived cAMP signals direct axonal targeting. Science 314:657-661. CrossRef

Medline

Kaneko-Goto T, Yoshihara S, Miyazaki H, Yoshihara Y (2008) BIG-2 mediates olfactory axon convergence to target glomeruli. Neuron 57: 834-846. CrossRef Medline

Kerr MA, Belluscio L (2006) Olfactory experience accelerates glomerular refinement in the mammalian olfactory bulb. Nat Neurosci 9:484486. CrossRef Medline

Kimmel CB, Ballard WW, Kimmel SR, Ullmann B, Schilling TF (1995) Stages of embryonic development of the zebrafish. Dev Dyn 203:253-310. CrossRef Medline

Koide T, Miyasaka N, Morimoto K, Asakawa K, Urasaki A, Kawakami K, Yoshihara Y (2009) Olfactory neural circuitry for attraction to amino acids revealed by transposon-mediated gene trap approach in zebrafish. Proc Natl Acad Sci U S A 106:9884-9889. CrossRef Medline 
Lakhina V, Marcaccio CL, Shao X, Lush ME, Jain RA, Fujimoto E, Bonkowsky JL, Granato M, Raper JA (2012) Netrin/DCC signaling guides olfactory sensory axons to their correct location in the olfactory bulb. J Neurosci 32:4440-4456. CrossRef Medline

Li J, Mack JA, Souren M, Yaksi E, Higashijima S, Mione M, Fetcho JR, Friedrich RW (2005) Early development of functional spatial maps in the zebrafish olfactory bulb. J Neurosci 25:5784-5795. CrossRef Medline

Macdonald R (1999) Zebrafish immunohistochemistry. Methods Mol Biol 127:77-88. CrossRef Medline

Mack-Bucher JA, Li J, Friedrich RW (2007) Early functional development of interneurons in the zebrafish olfactory bulb. Eur J Neurosci 25:460-470. CrossRef Medline

Madelaine R, Garric L, Blader P (2011) Partially redundant proneural function reveals the importance of timing during zebrafish olfactory neurogenesis. Development 138:4753-4762. CrossRef Medline

Manzini I, Heermann S, Czesnik D, Brase C, Schild D, Rössler W (2007) Presynaptic protein distribution and odour mapping in glomeruli of the olfactory bulb of Xenopus laevis tadpoles. Eur J Neurosci 26:925-934. CrossRef Medline

Mathuru AS, Kibat C, Cheong WF, Shui G, Wenk MR, Friedrich RW, Jesuthasan S (2012) Chondroitin fragments are odorants that trigger fear behavior in fish. Curr Biol 22:538-544. CrossRef Medline

Miyasaka N, Sato Y, Yeo SY, Hutson LD, Chien CB, Okamoto H, Yoshihara Y (2005) Robo2 is required for establishment of a precise glomerular map in the zebrafish olfactory system. Development 132:1283-1293. CrossRef Medline

Miyasaka N, Knaut H, Yoshihara Y (2007) Cxcl12/Cxcr4 chemokine signaling is required for placode assembly and sensory axon pathfinding in the zebrafish olfactory system. Development 134:2459-2468. CrossRef Medline

Miyasaka N, Morimoto K, Tsubokawa T, Higashijima S, Okamoto H, Yoshihara Y (2009) From the olfactory bulb to higher brain centers: genetic visualization of secondary olfactory pathways in zebrafish. J Neurosci 29:4756-4767. CrossRef Medline

Mombaerts P (2006) Axonal wiring in the mouse olfactory system. Annu Rev Cell Dev Biol 22:713-737. CrossRef Medline

Nüsslein-Volhard C, Dahm R (2002) Zebrafish: a practical approach (Nüsslein-Volhard C, Dahm R, eds). Oxford: Oxford UP.

Oliva AM, Jones KR, Restrepo D (2008) Sensory-dependent asymmetry for a urine-responsive olfactory bulb glomerulus. J Comp Neurol 510:475-483. CrossRef Medline

Parichy DM, Elizondo MR, Mills MG, Gordon TN, Engeszer RE (2009) Normal table of postembryonic zebrafish development: staging by externally visible anatomy of the living fish. Dev Dyn 238:2975-3015. CrossRef Medline

Pomeroy SL, LaMantia AS, Purves D (1990) Postnatal construction of neu- ral circuitry in the mouse olfactory bulb. J Neurosci 10:1952-1966. Medline

Potter SM, Zheng C, Koos DS, Feinstein P, Fraser SE, Mombaerts P (2001) Structure and emergence of specific olfactory glomeruli in the mouse. J Neurosci 21:9713-9723. Medline

Ressler KJ, Sullivan SL, Buck LB (1993) A zonal organization of odorant receptor gene expression in the olfactory epithelium. Cell 73:597-609. CrossRef Medline

Sakano H (2010) Neural map formation in the mouse olfactory system. Neuron 67:530-542. CrossRef Medline

Sato Y, Miyasaka N, Yoshihara Y (2005) Mutually exclusive glomerular innervation by two distinct types of olfactory sensory neurons revealed in transgenic zebrafish. J Neurosci 25:4889-4897. CrossRef Medline

Schaefer ML, Finger TE, Restrepo D (2001) Variability of position of the P2 glomerulus within a map of the mouse olfactory bulb. J Comp Neurol 436:351-362. CrossRef Medline

Schmid B, Schindelin J, Cardona A, Longair M, Heisenberg M (2010) A high-level 3D visualization API for Java and ImageJ. BMC Bioinformatics 11:274. CrossRef Medline

Stevens CB, Halloran MC (2005) Developmental expression of sema3G, a novel zebrafish semaphorin. Gene Expr Patterns 5:647-653. CrossRef Medline

Vassar R, Ngai J, Axel R (1993) Spatial segregation of odorant receptor expression in the mammalian olfactory epithelium. Cell 74:309-318. CrossRef Medline

Waldman B (1982) Quantitative and developmental analyses of the alarm reaction in the Zebra Danio, Brachydanio rerio. Copeia 1:1-9.

Whitlock KE, Westerfield M (1998) A transient population of neurons pioneers the olfactory pathway in the zebrafish. J Neurosci 18:89198927. Medline

Yanicostas C, Herbomel E, Dipietromaria A, Soussi-Yanicostas N (2009) Anosmin-1a is required for fasciculation and terminal targeting of olfactory sensory neuron axons in the zebrafish olfactory system. Mol Cell Endocrinol 312:53-60. CrossRef Medline

Yu CR, Power J, Barnea G, O’Donnell S, Brown HE, Osborne J, Axel R, Gogos JA (2004) Spontaneous neural activity is required for the establishment and maintenance of the olfactory sensory map. Neuron 42:553-566. CrossRef Medline

Zheng C, Feinstein P, Bozza T, Rodriguez I, Mombaerts P (2000) Peripheral olfactory projections are differentially affected in mice deficient in a cyclic nucleotide-gated channel subunit. Neuron 26:81-91. CrossRef Medline

Zou DJ, Feinstein P, Rivers AL, Mathews GA, Kim A, Greer CA, Mombaerts P, Firestein S (2004) Postnatal refinement of peripheral olfactory projections. Science 304:1976-1979. CrossRef Medline 